\title{
THROUGHPUT MODEL FOR COUPLED Reconfigurable Product Line
}

\author{
HASAN, F.; JAIN, P.K. \& DINESH, K.
}

Abstract: In today's global manufacturing era, one of the important challenges faced by manufacturers is how to deal with stochastic demand and ever changing customer needs and requirements. Reconfigurable manufacturing systems are recognized as next generation manufacturing systems capable of meeting the above requirements economically by providing the exact functionality and capacity as and when required. Some core characteristics of these systems include scalability, convertibility, diagnosability and modularity. The design and operation of these systems are built around a part family. Though most the past research takes into account the optimization of some design parameter but still performance parameters like throughput or productivity, resource utilization, reliability and availability, needs to be investigated to evaluate performance of such systems. This chapter presents a mathematical model to evaluate the throughput or productivity of such systems. The developed model is employed to calculate throughput values for a 3station coupled reconfigurable product line.

Key words: Reconfigurable Manufacturing System (RMS), performance model, throughput, product line
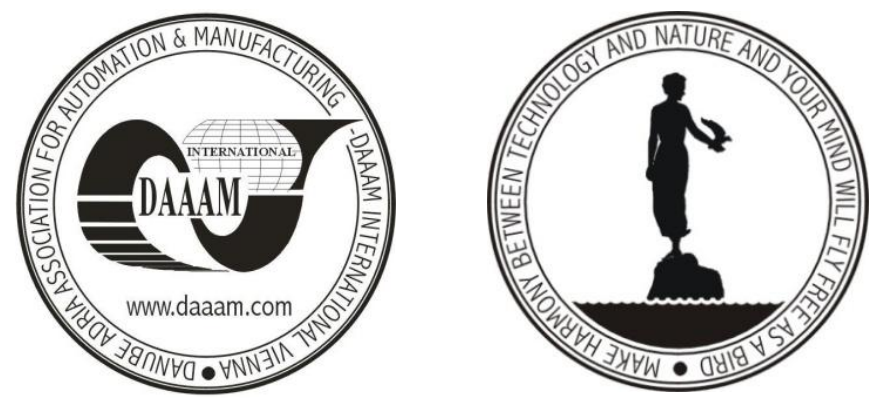

Authors' data: Research Scholar Hasan, F[aisal]; Prof. Jain, P[ramod] K[umar]; Prof. Dinesh, K[umar], Mechanical \& Industrial Engineering Department, IIT Roorkee, INDIA, faisalhasan123@rediffmail.com, pjainfme@iitr.ernet.in, dinesfme@iitr.ernet.in

This Publication has to be referred as: Hasan, F[aisal]; Jain, P[ramod] K[umar] \& Dinesh, K[umar] (2012). Throughput Model for Coupled Reconfigurable Product Line, Chapter 09 in DAAAM International Scientific Book 2012, pp. 095-106, B. Katalinic (Ed.), Published by DAAAM International, ISBN 978-3-901509-86-5, ISSN 1726-9687, Vienna, Austria

DOI:10.2507/daaam.scibook.2012.09 
$\overline{\text { Hasan, F.; Jain, P.K. \& Dinesh, K.: Throughput Model for Coupled Reconfigurable... }}$

\section{Introduction}

In today's era of globalization, all the manufacturing enterprises are facing challenges related to costs, wide degree of customized products, lower product life cycle and an ever increasing threat from the competitors of how quickly the manufacturing facilities are responsive with market demands and customer needs. To have a cutting edge, the manufacturers must use resources or facilities that not only produce their goods with high productivity and lower cost but also provide them with some degree of flexibility because of rapid changes in market and customer needs. The manufacturing systems have covered a wide journey of its transformation from Dedicated Manufacturing Line (DML) to Flexible Manufacturing Systems (FMS) and then to Reconfigurable Manufacturing System (RMS). Earlier, DML enjoyed wide acceptance among manufacturers because the product life cycle was long and there was no change in the product design over long period of time and the only requirement was high production volume at a reduced cost. Since, producing product variety was impossible on these dedicated lines and thus the need arises to switch over to some new systems. In the initial stages of its introduction FMSs were seen as a revolutionary tool by the manufacturers as it is capable of producing a variety of products by simply reprogramming and automating the system (Koren et al., 1998). But because of some drawbacks like expensive CNC machines, low productivity, high production and installation costs these FMSs didn't find wider acceptability in the manufacturing sector.

A Reconfigurable Manufacturing System offers the capability which allows for quick launch of new products with customized design and stochastic demand pattern. RMS is considered as a responsive manufacturing system whose production capacity is adjusted to market fluctuations and whose functionality is adaptable to a variety of new products (Koren et al., 1999). According to Koren et al., (1999) "An RMS is designed at the outset for rapid change in structure, as well as in hardware and software components, in order to quickly adjust production capacity and functionality within a part family in response to sudden changes in market or in regulatory requirements". In summary, it can be concluded that the basic objective of RMS is to provide the functionality and scalability as and when needed. Thus, according to Mehrabi et al. (2000) a given RMS configuration can be dedicated or flexible, or in between, and can be changed as per requirements.

Reconfigurable Machines (RMs) are considered to be the most important components in RMS (Koren et al., 1999). These RMs are modular machines with flexible capacity and functionality. These machines are composed of basic and auxiliary components or modules. Basic or essential components are structural components which imparts define shape to these machines. On the other hand, auxiliary components are flexible in nature which may be added or removed easily to have variable capacity and functionality. A product line can be installed on the shop floor by arranging RMs serially to perform operations on the jobs in some desired sequence. For any station on the product line there may be several candidates RMs available to carry out the operation with varying operation times. Thus, several product line configurations can be obtained by selecting different RMs at stations. 
The objective is to develop a model for calculating the throughput values of these product lines and determine the optimal product line configuration having maximum throughput.

In recent years, work has been carried out mostly on optimal designing of these systems in terms of reconfiguration costs, reconfiguration planning, layouts, availability and reliability. However, performance aspects like throughput or productivity, resource utilization, make span time etc. still needs to be investigated in order to evaluate the performance of these systems. Some of the literature reviewed has been presented in the following section.

\section{Literature Review}

Meng et al. (2004) studied the layout problem in context of RMS and the performance of feasible layout was evaluated in terms of work in process inventory and product lead time. Montreuil and Laforge (1992) presents a proactive methodology for designing dynamic layouts for expansion phase of manufacturing systems. Work on designing and optimizing reconfigurable layouts has been done by Kouvelis et al. (1992), Yang and Peters (1998) and Kochhar and Heragu (1999). The concept of scalability has wider significance for RMS as it takes into account stochastic nature of demand pattern. The concept of machine level scalability was given by Spicer et al. (2002) by introducing the concept of Reconfigurable Machine Tools (RMTs). According to Spicer et al. (2002), system level scalability can be changed by adding or removing auxiliary modules on these RMTs. Design of scalable RMS was proposed by Spicer and Carlo (2007) based on optimizing the cost parameter to achieve the desired scalability. Son et al. (2001) proposed stage paralleling approach to model scalability of RMS. Renna (2009) proposed a policy to manage capacity exchange or scalability for RMS. Model for capacity scalability in RMS based on control theoretic approach was proposed by Dief and ElMaraghy (2006a, b). Asl and Ulsoy (2002a) presented an approach to capacity scalability modelling in RMS based on the use of feedback control theory to manage the capacity scalability problem. Another approach for capacity management in RMS with stochastic market demand was presented by Asl and Ulsoy (2002b) where an optimal region for the capacity scalability management policy based on Markov decision theory was presented.

The literature on the performance evaluation aspect of RMS showed that cost is one of the single most commonly used parameter for the evaluation of such systems (Gallan et al., 2007; Matta et al., 2008; Yigit et al., 2003; Son et al., 2001; Xiaobo et al., 2000, 2001). Some other performance parameters taken into account include throughput (Yang and $\mathrm{Hu}, 2000$; Tang et al., 2004), ramp-up time (Mehrabi et al., 2000), work in process inventory (Meng et al., 2004), service level for part families (Xiaobo et al., 2001), availability and reliability (Koren, 1998). Youssef and ElMaraghy (2007) presented the various performance measure parameters used in the past while studying the optimal configuration selection for RMS. Theoretical performance evaluation models using AHP and fuzzy were propose by Golec and Taskin (2007) for manufacturing system in general. The factors which Golec and Taskin (2007) took into account for their performance model include cost, flexibility, 
quality, speed and dependability. Xiaobo et al. (2001) studied the performance of an RMS by defining the service level for part families. Based on literature reviewed, a holistic RMS model (Fig. 1) has been proposed which takes into account the various performance measure parameters along with the design and control factors measure which must be evaluated in order to assess the real potential of RMSs.

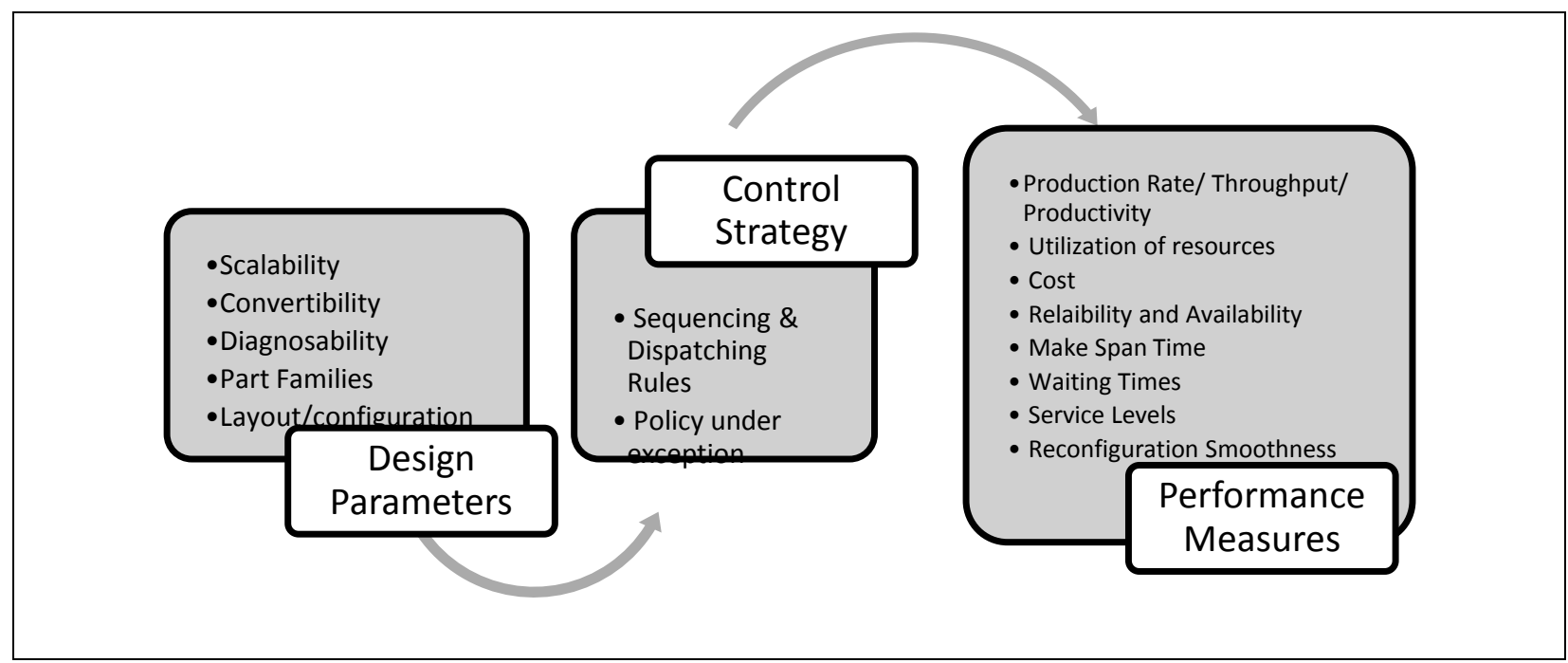

Fig. 1. A holistic approach towards RMS design and performance issues

\section{Throughput Model}

Consider an RMS module library consisting of three basic and four auxiliary modules (Fig. 2). A total of $12(3 \times 4)$ distinct RMs can be assembled by combining a basic and auxiliary module. These RMs have different operational capabilities like operation-3 at station- 1 can be performed on $R M_{1}^{4}$ and $R M_{2}^{4}$ with different mean operation times values, similarly candidate RMs for operation- 4 and operation-7 are $R M_{2}^{1}$ and $R M_{1}^{3}, R M_{2}^{2}$ and $R M_{3}^{4}$ respectively. The candidates RMs are serially arranged in the desired sequence to form a 3 -station product line. Six $(2 \times 1 \times 3)$ different reconfigurable product line configurations can be configured to execute the production process. Operations 3, 4 and 7 are required on jobs at stations 1,2 and 3 respectively. The objective is to calculate the throughput values for each of the six product lines and subsequently selecting the optimum line as the one giving maximum throughput value. Since, the total work content (TWC) for all product lines is distinct, thus, in order to compare their performance in terms of throughput the mean operation time values are to be normalized. The normalizing factor $(N F)$ can be calculated as

$$
N F=\frac{n}{\sum_{i=1}^{n}(O T)_{i}}
$$

Normalized mean operation time at any station can be calculated as

$$
\mu_{n}=(O T)_{n} * N F
$$




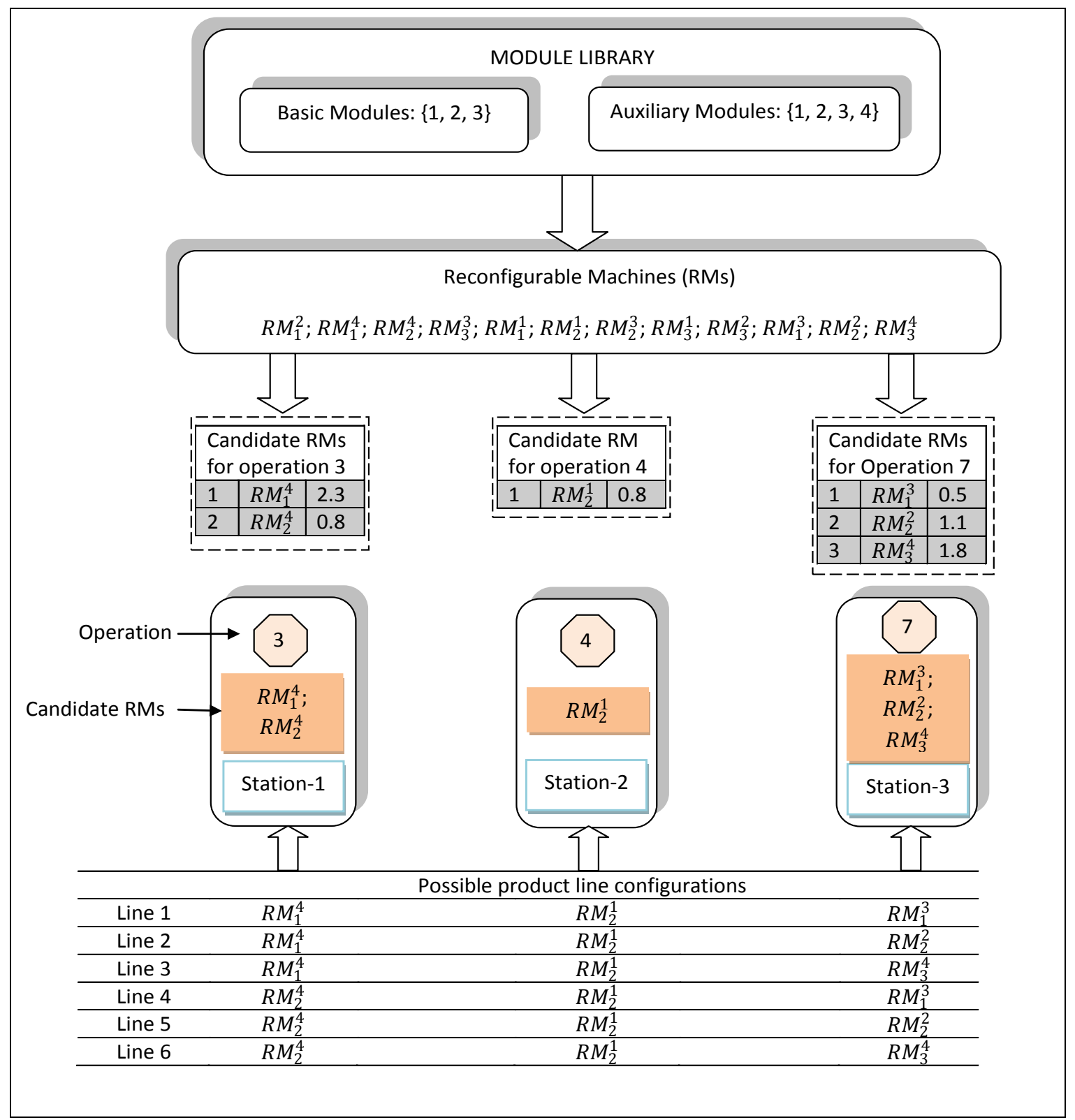

Fig. 2. A 3-station coupled product line with possible configurations

\subsection{Notations and Abbreviations}

$R M_{p}^{q}$ : Reconfigurable machine assembled using $p^{\text {th }}$ basic and $q^{\text {th }}$ auxiliary module.

$n \quad:$ Number of station or stages on the product line $(n=1,2,3)$.

$S \quad$ : Starved state of any station.

$B \quad$ : Blocked state of any station.

$W \quad$ : Working or operating state of any station.

$S_{t}:\{S, B, W\}$ : State Set indicating the possible three states of individual stations.

$P_{i j k}(t) \quad:$ Transient state probability that at time " $\mathrm{t}$ " the station-1 is in state " $\mathrm{i}$ ", station-2 is in state " $\mathrm{j}$ " and station-3 is in state " $k$ ", where $i, j \& k \epsilon$ $S_{t}:\{S, B, W\}$

$P_{i j k} \quad:$ Steady state probability

$(O T)_{n} \quad$ : Mean operation time at $n^{\text {th }}$ station.

$\mu_{n} \quad$ : Normalized mean operation time at $n^{\text {th }}$ station. 
$\alpha_{n} \quad:$ Operation rate at $n^{\text {th }}$ station, where, $\alpha_{n}=\frac{1}{\mu_{n}}$

$\Delta \quad$ : Small time interval in which any event can occur on any station on the production line.

$R \quad$ : Production Rate or throughput from the product line.

\subsection{Assumptions}

(i) Each RMT is modular in nature and composed of basic and auxiliary modules.

(ii) First station on the product line can never be in a blocked state while the last station can never be in starved state.

(iii) The various values of mean operation time at the RMs are exponentially distributed.

(iv) The transfer time of jobs between the stations is negligible.

(v) No intermediate buffer capacities are considered i.e the product line is strongly coupled.

(vi) There is no failure of RMs on any of the stations during the production run.

(vii) An event is defined as a change in the state of any station and thereby a change in the system state.

(viii) The time interval $\Delta$ is considered to be so small that only single event can occur during this interval i.e. probability of occurrences of two simultaneous events is negligible and thus it is not considered.

\subsection{Mathematical Model}

Jobs move from one station to subsequent stations as per the required operations sequence. These stations comprising of RMs are highly coupled or linked because no intermediate buffer capacities are considered. These linkages impose certain constraints upon the working of these stations. Suppose that $n^{\text {th }}$ station on the production line has finished the processing of a job then logically this station can only process the next job under two conditions. Firstly, it should be able to dispose the finished job to $(n+1)^{t h}$ station provided that $(n+1)^{\text {th }}$ station is idle and waiting to get the job from preceeding $n^{\text {th }}$ station. Secondly, $n^{\text {th }}$ station should immediately get a job from preceding $(n-1)^{t h}$ station provided that $(n-1)^{t h}$ station have finished processing on the job and is waiting to pass on the job to $n^{\text {th }}$ station. If there had been considerable intermediate buffer capacities, the various stations on the line worked independently of each other and such line is known as a delinked or decoupled product line. However, in this case all stations on the product line are not operating all the time because of coupling effect. Thus, the various stations on the line can be in any one of the following states at any instant of time.

Working: This state refers that the work piece is being processed at a station.

Blocked: This refers to the state in which an $n^{\text {th }}$ station has processed the job but is not able to dispose it off to next $(n+1)^{t h}$ station. This is because $(n+1)^{t h}$ station is either busy or blocked.

Starved: It refers to the condition in which a station on the product line has finished processing on a job and passed this job to the next station but it is not able to get the 
job from its preceding station. This condition occurs because the preceding station is either in operating state or in starved state.

For calculating the throughput from the system, the above three states are assigned alphabetical codes. The starved state is represented by " $S$ ", the blocked state is represented by" $B$ " while the working or operating state is represented by " $W "$. A combination of states of individual station gives a particular state of the product line, for e.g. state " $W W W$ "refers to a condition in which all the three stations on the product line are in operating state at a particular instant of time. Depending upon the various possible combinations of the station states, the line can have numerous states. However, not all combinations of these system states are valid. For example, the line cannot have a blocked station preceding a starved station i.e. the combination "..SB.." is an invalid line state. Since, it was assumed that first station on the production line will always have abundant supply of jobs, thus, first station on the line can never be starved (state- $S$ ). Similarly, it was assumed that the last station on the line can never be blocked (state- $B$ ) since it can always transfer its finished jobs to a large storage area. This helps in reducing to total number of system states. All the feasible and infeasible states are presented in Tab. 1.

The processing time at each station is assumed to be exponentially distributed with the following probability density function (pdf):

$$
f(t)=\alpha e^{-\alpha t}, \mathrm{t} \geq 0
$$

Since, $\alpha$ represents mean operation rate on a station, which means that on an average $\alpha$ number of jobs are processed on this station per unit time. The normalized mean processing time $\mu$ at any station is thus equals to $1 / \alpha$. The forgetfulness property of exponential distribution helps in finding a simplified expression for the probability that ongoing operation on a station will end in a small time interval $\Delta$, irrespective of the time " $t$ "elapsed since the last event took place. The probability that an ongoing operation on this station ends in a small time interval $\Delta$ is equal to $\alpha . \Delta$. Similarly, the probability that an ongoing operation at a station will not end in the time interval $\Delta$ is given by $(1-\alpha . \Delta)$. The time interval $\Delta$ is assumed to be small so that only one event can occur on the whole line within this time interval. In other words, the probability of two or more events occurring simultaneously in time interval $\Delta$ is negligible or zero.

The transition of feasible product line states within time $\Delta$ can be formulated as, say for state BBW, the following events may occur during time interval $\Delta$ :

EVENT 1: The product line state BBW at time $\mathrm{t}$ remains as BBW after time $(\mathrm{t}+\Delta)$ if working at station-3 is not over within time interval $\Delta$.

EVENT 2: The state BWW at time t, may changed to state BBW after time $\Delta$, if working at station-2 is over within time $\Delta$. When working is complete at station-2, its state changes from "W" to " $\mathrm{B}$ " as working is still in progress at station-3 due to which station-2 is not able to dispose the finished job and accordingly it becomes blocked. 
Hasan, F.; Jain, P.K. \& Dinesh, K.: Throughput Model for Coupled Reconfigurable...

EVENT 3: The state WBW may switch to BBW if working at station-1 is over within time interval $\Delta$. Station-1 state changes from working to blocked as the job cannot be transferred to the next station because still the next station is engaged.

\begin{tabular}{|c|c|c|c|c|c|c|}
\hline \multicolumn{2}{|c|}{ Feasible States } & \multicolumn{5}{|c|}{ Infeasible States } \\
\hline BBW & WSW & SSS & SBB & SWW & BBS & WBS \\
\hline BWS & WBW & SSB & SBW & BSS & BBB & WBB \\
\hline BWW & WWS & SSW & SWS & BSB & BWB & WWB \\
\hline WSS & WWW & SBS & SWB & BSW & WSB & \\
\hline
\end{tabular}

Tab. 1. Feasible and Infeasible states for the Production Line

Similarly, the transition of all the feasible states from time $t$ to $(t+\Delta)$ can be formulated. The complete transition of these feasible states is presented in Table 2 .

\begin{tabular}{|l|l|l|l|l|}
\hline System State at $(\mathrm{t}+\Delta)$ & \multicolumn{4}{|c|}{ System State at time "t" } \\
\hline BBW & $B B W_{1-\alpha_{1}}$ & $B W W_{\alpha_{2}}$ & $W B W_{\alpha_{1}}$ & \\
\hline BWS & $B W S_{1-\alpha_{2}}$ & $B W W_{\alpha_{3}}$ & $W W S_{\alpha_{1}}$ & \\
\hline BWW & $B W W_{1-\alpha_{2}, 1-\alpha_{3}}$ & $W W W_{\alpha_{1}}$ & & \\
\hline WSS & $W S S_{1-\alpha_{1}}$ & $W S W_{\alpha_{3}}$ & & \\
\hline WSW & $W S W_{1-\alpha_{1}, 1-\alpha_{3}}$ & $W B W_{\alpha_{3}}$ & $W W S_{\alpha_{2}}$ & \\
\hline WBW & $W B W_{1-\alpha_{1}, 1-\alpha_{3}}$ & $W W W_{\alpha_{2}}$ & & \\
\hline WWS & $W W S_{1-\alpha_{1}, 1-\alpha_{2}}$ & $W S S_{\alpha_{1}}$ & $W W W_{\alpha_{3}}$ & \\
\hline WWW & $W W W_{1-\alpha_{1}, 1-\alpha_{2}, 1-\alpha_{3}}$ & $B B W_{\alpha_{3}}$ & $B W S_{\alpha_{2}}$ & $W S W_{\alpha_{1}}$ \\
\hline
\end{tabular}

Tab. 3. State transition of the product line form time $\mathrm{t}$ to $(\mathrm{t}+\Delta)$

Let $P_{i j k}(t)$ represents the transient probability that at time " $t$ ", the first station is in state " $i$ ", second is in state " $j$ " and third is in state " $k$ ", where $i, j, k \in S_{t}:\{S, B, W\}$. If $\alpha_{1}$ , $\alpha_{2}$ and $\alpha_{3}$ be the operation rates at first, second and third stations on the production line respectively. The transient state probability equation for the production line can be derived as follows:

$$
P_{B B W}(t+\Delta)=P_{B B W}(t) \cdot\left(1-\alpha_{3} \Delta\right)+P_{B W W}(t) \cdot \alpha_{2} \Delta+P_{W B W}(t) \cdot \alpha_{1} \Delta
$$

Equation (4) can be rewritten as

$$
\begin{aligned}
& \lim _{\Delta \rightarrow 0} \frac{P_{B B W}(t+\Delta)-P_{B B W}(t)}{\Delta}=-\alpha_{3} P_{B B W}(t)+\alpha_{2} P_{B W W}(t)+\alpha_{1} P_{W B W}(t) \\
& o r, \frac{d P_{B B W}(t)}{d t}=-\alpha_{3} P_{B B W}(t)+\alpha_{2} P_{B W W}(t)+\alpha_{1} P_{W B W}(t)
\end{aligned}
$$

Under steady state equation (6) can be written as 
$-\alpha_{3} P_{B B W}+\alpha_{2} P_{B W W}+\alpha_{1} P_{W B W}=0$

Similarly, the following steady state probabilistic working equations for all the feasible system states can be derived.

$$
\begin{gathered}
-\alpha_{2} P_{B W S}+\alpha_{3} P_{B W W}+\alpha_{1} P_{W W S}=0 \\
-\left(\alpha_{2}+\alpha_{3}\right) P_{B W W}+\alpha_{1} P_{W W W}=0 \\
-\alpha_{1} P_{W S}+\alpha_{3} P_{W S W}=0 \\
-\left(\alpha_{1}+\alpha_{3}\right) P_{W S W}+\alpha_{3} P_{W B W}+\alpha_{2} P_{W W S}=0 \\
-\left(\alpha_{1}+\alpha_{3}\right) P_{W B W}+\alpha_{2} P_{W W W}=0 \\
-\left(\alpha_{1}+\alpha_{2}\right) P_{W W S}+\alpha_{1} P_{W S S}+\alpha_{3} P_{W W W}=0 \\
-\left(\alpha_{1}+\alpha_{2}+\alpha_{3}\right) P_{W W W}+\alpha_{1} P_{W S W}+\alpha_{2} P_{B W S}+\alpha_{3} P_{B B W}=0
\end{gathered}
$$

and, the law of probability

$$
P_{B B W}+P_{B W S}+P_{B W W}+P_{W S S}+P_{W S W}+P_{W B W}+P_{W W S}+P_{W W W}=1
$$

The steady state throughput $(R)$ for the product line can be obtained by simply calculating the production rate across any station on the line. This is because, under a steady state, the production rate is same across all stations on the production line. The fluid flow analogy is helpful to understand this, consider incompressible fluid flow through pipe of varying X-sectional area as shown in Fig. 4, then under steady state the flow rate $(Q)$ through the system can be measure as

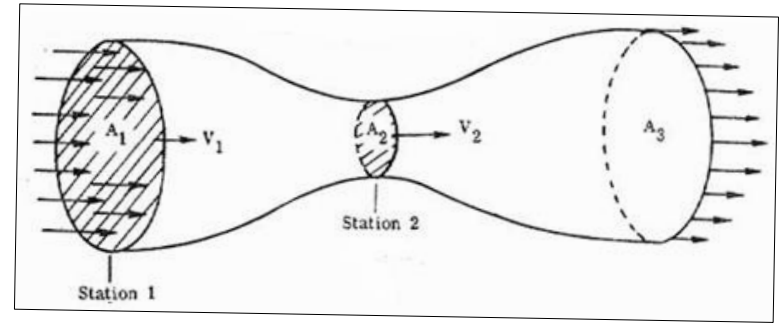

Fig.3. Fluid Flow through varying $\mathrm{X}$-sectional area pipe

$$
Q=A_{1} v_{1}=A_{2} v_{2}
$$

For the present problem, the pipe $\mathrm{X}$-sectional areas $A_{1}$ or $A_{2}$ are analogous to sum of the probabilities that an station is in working state while the other two stations can 
$\overline{\text { Hasan, F.; Jain, P.K. \& Dinesh, K.: Throughput Model for Coupled Reconfigurable... }}$

have any state belonging to set $S_{t}:\{S, B, W\}$ while the velocities $v_{1}$ or $v_{2}$ are analogous to the operation rate at the station which is in working state. Thus, mathematically, the production rate or throughput $(R)$ which is analogous to flow rate $(Q)$ can be written as

$$
R=\sum P_{W j k} \cdot \alpha_{1}=\sum P_{i W k} \cdot \alpha_{2}=\sum P_{i j W} \cdot \alpha_{3}
$$

\section{Results}

Random data for mean operation time for a 3-station reconfigurable product line is generated and is normalized using equations (1) \& (2) and is presented in Table 3.

\begin{tabular}{|c|c|c|c|c|c|c|c|}
\hline \multirow[b]{2}{*}{$\begin{array}{l}\text { Product } \\
\text { Line }\end{array}$} & \multicolumn{3}{|c|}{ Mean operation time } & \multirow[b]{2}{*}{$\mathrm{NF}$} & \multicolumn{3}{|c|}{ Normalized mean operation time } \\
\hline & $\begin{array}{c}\text { Station- } \\
1\end{array}$ & $\begin{array}{l}\text { Station- } \\
2\end{array}$ & $\begin{array}{c}\text { Station- } \\
3\end{array}$ & & Station-1 & $\begin{array}{c}\text { Station- } \\
2\end{array}$ & Station-3 \\
\hline 1 & 2.3 & 1.0 & 0.5 & 0.789 & 1.815 & 0.789 & 0.395 \\
\hline 2 & 2.3 & 1.0 & 1.3 & 0.652 & 1.499 & 0.652 & 0.848 \\
\hline 3 & 2.3 & 1.0 & 1.8 & 0.588 & 1.352 & 0.588 & 1.058 \\
\hline 4 & 0.8 & 1.0 & 0.5 & 1.304 & 1.043 & 1.304 & 0.652 \\
\hline 5 & 0.8 & 1.0 & 1.3 & 0.968 & 0.774 & 0.968 & 1.258 \\
\hline 6 & 0.8 & 1.0 & 1.8 & 0.833 & 0.666 & 0.833 & 1.499 \\
\hline
\end{tabular}

Tab. 3. Mean operation times at stations on the product line

For the production line data, equations (7) to (14) are solved in MATLAB using matrix inversion method to obtain the values of steady state probabilities of different feasible system states along with throughput values. The values obtained are presented in Table 4 for various product line configurations.

\begin{tabular}{|c|c|c|c|c|c|c|c|c|c|}
\hline $\begin{array}{c}\text { Product } \\
\text { Line }\end{array}$ & $\mathrm{P}_{\mathrm{BBW}}$ & $\mathrm{P}_{\mathrm{BWw}}$ & $\mathrm{P}_{\mathrm{WBW}}$ & $\mathrm{P}_{\mathrm{BWS}}$ & $\mathrm{P}_{\mathrm{WwS}}$ & $\mathrm{P}_{\mathrm{www}}$ & $\mathrm{P}_{\mathrm{WSS}}$ & $\mathrm{P}_{\mathrm{WSW}}$ & $\mathrm{R}(\%)$ \\
\hline 1 & 0.0080 & 0.0072 & 0.0204 & 0.1083 & 0.2160 & 0.0496 & 0.4849 & 0.1055 & 48.29 \\
\hline 2 & 0.0787 & 0.0245 & 0.0827 & 0.0828 & 0.1471 & 0.0996 & 0.3095 & 0.1751 & 54.29 \\
\hline 3 & 0.1477 & 0.0319 & 0.1154 & 0.0672 & 0.1139 & 0.1142 & 0.2299 & 0.1798 & 55.66 \\
\hline 4 & 0.0508 & 0.0528 & 0.0390 & 0.3363 & 0.1844 & 0.1268 & 0.1292 & 0.0807 & 53.71 \\
\hline 5 & 0.2750 & 0.1128 & 0.0790 & 0.1845 & 0.0781 & 0.1596 & 0.0423 & 0.0687 & 55.26 \\
\hline 6 & 0.3981 & 0.1189 & 0.0818 & 0.1280 & 0.0495 & 0.1478 & 0.0233 & 0.0525 & 53.31 \\
\hline
\end{tabular}

Tab. 4. Probability and throughput values obtained for product line configurations

The optimum product line configuration from throughput consideration was found to be line configuration-5. The maximum throughput of $55.26 \%$ can be achieved by operating this line. 


\section{Summary and Future Research}

The mathematical model developed is useful in calculating throughput values of different product line configurations. Apart from other design criterions like cost, ramp up time, scalability and convertibility, throughput must also be taken as one of the most important criterion for designing and operating these kinds of manufacturing systems. In methodology developed can be extended to reconfigurable line have higher number of stages or stations. Although, it is hard to develop a generalized model for " $\mathrm{N}$ " number of stations on the line. The result obtained using this model is exact as compared to simulated models. The model can also be extended for system taking into consideration the reliability aspect and intermediate buffer spaces between stations. Certain strategies like mean operation time synchronization across stations may be looked into to improve the productivity from these systems.

\section{References}

Asl, R; and Ulsoy, A. (2002a). Capacity management via feedback control in reconfigurable manufacturing systems. Proceeding of Japan-USA symposium on flexible manufacturing automation, Hiroshima, Japan

Asl, R; and Ulsoy, A. (2002b). Capacity management in reconfigurable manufacturing systems with stochastic market demand. Proceeding of ASMEinternational mechanical engineering congress and exposition

Deif, A. M.; and ElMaraghy, W. (2006a). Effect of reconfiguration costs on planning for capacity scalability in reconfigurable manufacturing systems. International Journal of Flexible Manufacturing Systems, Vol. 18, No. 3, pp. 225-238

Deif, A.; and ElMaraghy, H. (2006b). Investigating optimal capacity scalability scheduling in a reconfigurable manufacturing system. International Journal of Advance Manufacturing Technology, Vol. 32, pp. 557-562

Galan, R.; Racero, J.; Eguia, I.; and Garcia, J. (2007). A systematic approach for product families formation in Reconfigurable Manufacturing Systems. Robotics and Computer-Integrated Manufacturing, Vol. 23, No. 5, pp. 489-502

Golec, A; and Taskin, H. (2007). Novel methodologies and a comparative study for manufacturing systems performance evaluations. Information Sciences, Vol. 177, No. 23, pp. 5253-5274

Kochhar, J. S.; and Heragu, S. S. (1999). Facility layout design in a changing environment. International Journal of Production Research, Vol. 37, pp. 2429-2446

Koren, Y., Hu, S. J., \& Weber, T. W. (1998). Impact of Manufacturing System Configuration on Performance. Annals of CRIP, Vol. 47, No. 1, pp. 369-372.

Koren, Y.; Hiesel, U.; Jovane, F.; Moriwaki, T.; Pritschow, G.; Ulsoy, G. \& Van, B. H. (1999). Reconfigurable Manufacturing Systems. Annals of the CIRP, Vol. 48, No. 2, pp. 527-540

Kouvelis, P.; and Chiang, W. (1992). Simulated annealing approach for single row layout problems in flexible manufacturing systems. International Journal of Production Research, Vol. 30, pp. 717-732 
Matta, A.; Tomasella, M.; Clerici, M., and Sacconi, S. (2008). Optimal reconfiguration policy to react to product changes. International Journal of Production Research, Vol. 46, No. 10, pp. 2651-2673

Mehrabi, M. G.; Ulsoy, A. G. \& Koren, Y. (2000). Reconfigurable manufacturing systems: Key to future manufacturing. Journal of Intelligent Manufacturing, Vol. 11, No. 4, pp. 403-419

Meng, G.; Heragu, S. S.; and Zijm, H. (2004). Reconfigurable layout problem. International Journal of Production Research, Vol. 42, pp. 4709-4729

Montreuil, B.; and Laforge, A. (1992). Dynamic layout design given a scenario tree of probable futures. European Journal of Operational Research, Vol. 63, pp. 271-286

Renna, P. (2009). Capacity reconfiguration management in reconfigurable manufacturing systems. The International Journal of Advanced Manufacturing Technology, 46(1-4), 395-404

Son, S.-Y.; Olsen, T. L.; and Yip-Hoi, D. (2001). An approach to scalability and line balancing for reconfigurable manufacturing systems. Integrated Manufacturing Systems, Vol. 12, No. 7, pp. 500-511

Spicer, P.; and Carlo, H. J. (2007). Integrating Reconfiguration Cost into the Design of Multi-Period Scalable Reconfigurable Manufacturing Systems. Journal of Manufacturing Science and Engineering, Vol. 129, No. 1, pp. 202-210

Spicer, P.; Koren, Y.; Shpitalni, M.; and Yip-Hoi, D. (2002). Design Principles for Machining System Configurations. CIRP Annals, Vol. 51, No. 1, pp. 275-280

Tang, L.; Yip-Hoi, D. M; Wang, W.; and Koren, Y. (2004). Concurrent linebalancing, equipment selection and throughput analysis for multi-part optimal line design. International Journal of Manufacturing Science and Production, Vol. 6, No. 1-2, pp. 71-81

Xiaobo, Z.; Jiancai, W.; and Zhenbi, L. (2000). A stochastic model of a reconfigurable manufacturing system, Part 1: A framework. International Journal of Production Research, Vol. 38, 2273-2285

Xiaobo, Z.; Wang, J.;and Luo, Z. (2001). A stochastic model of a reconfigurable manufacturing system - Part 4: Performance measure. International Journal of Production Research, Vol. 39, pp. 1113-1126

Yang, S; and Hu, S. J. (2000). Productivity analysis of a six CNC machine manufacturing system with different configurations. Proceedings of the 2000 Japan-USA flexible automation conference, Michigan, 499-505

Yang, T.; and Peters, B. A., (1998). Flexible machine layout design for dynamic and uncertain production environments. European Journal of Operational Research, Vol. 108, pp. 49-64

Yigit, A.; and Allahverdi, A. (2003). Optimal selection of module instances for modular products in reconfigurable manufacturing systems. International Journal of Production Research, Vol. 41, pp. 4063-4074

Youssef, A. M. A. \& ElMaraghy, H. A. (2007). Optimal configuration selection for reconfigurable manufacturing systems. International Journal of Flexible Manufacturing Systems, Vol. 19, No. 2, pp. 67-106 